\title{
A INFÂNCIA NO FIO DA NAVALHA: CONSTRUÇÃO TEÓRICA COMO AGIR ÉTICOi
}

CHILDHOOD ON THE RAZOR'S EDGE: THEORETICAL CONSTRUCTION AS ETHICAL ACTION

\author{
LA INFANCIA AL FILO DE LA NAVAJA: \\ CONSTRUCCIÓN TEÓRICA COMO HACER ÉTICO
}

Rita Ribes Pereira ${ }^{1}$, Lisandra Ogg Gomes², Conceição Firmina Seixas Silva ${ }^{3}$

\section{RESUMO}

O debate sobre a ética na pesquisa em Ciências Humanas, mais particularmente na pesquisa com crianças, é um tema candente no contexto brasileiro, assim como as condições de interlocução do pesquisador com os sujeitos que participarão de sua pesquisa têm ocupado um papel central. Considerando esse foco, nossa intenção é trazer para o centro do debate a dimensão ética que se faz presente na própria teoria, isto é, conceber a teoria como um agir ético. Partimos do pressuposto de que a pesquisa em Ciências Humanas sempre implica um outro, mesmo que não haja previsão de um trabalho de campo. O outro está incrustrado na teoria, seja naquilo que o conhecimento sistematizado pela humanidade já nos oferece como perspectiva de visada, seja naquilo que inauguramos com o nosso próprio pensar. Pensar, neste sentido, é um agir ético, na medida em que implica um outro e um posicionamento sobre esse outro. Quem é o outro-criança para os pesquisadores da infância? Que implicações éticas se impõem quando nos colocamos a pensar a infância? Por que pensar a infância? Para quê? Qual o lugar das crianças na teoria que produzimos sobre elas? Neste texto procuraremos perseguir essas indagações a partir da tensão que se dá entre participação e tutela, proteção e autoria, experiências de alteridade entre crianças e adultos na vida social que são postas em xeque no fazer teórico, posto que teorizar não implica apenas em descrever o mundo social, mas também em instaurá-lo.

PALAVRAS-CHAVE: Infância. Ética. Participação das Crianças. Proteção.

\section{ABSTRACT}

The debate on ethics in Human and Social Science research, particularly research concerning children, is an important theme in the Brazilian context. The study of the conditions under which researchers interact with subjects participating in the research has also played a central role. Given this focus, our intention is to bring to the center of the debate the ethical dimension present in the theory itself. That is, our intention is to conceive theory as an ethical action. We assume that research in the Human Sciences always involves an other, even

\footnotetext{
${ }^{1}$ Doutora em Educação - Pontifícia Universidade Católica do Rio de Janeiro (PUC-Rio) - Rio de Janeiro, RJ Brasil. Professora da Faculdade de Educação - Universidade do Estado do Rio de Janeiro (UERJ) - Rio de Janeiro, RJ - Brasil. E-mail: ritaribes@uol.com.br

${ }^{2}$ Doutora em Educação - Universidade de São Paulo (USP) - São Paulo, SP - Brasil. Professora da Faculdade de Educação - Universidade do Estado do Rio de Janeiro (UERJ) - Rio de Janeiro, RJ - Brasil. E-mail: lisandraogg@yahoo.com.br

${ }^{3}$ Doutora em Psicologia - Universidade Federal do Rio de Janeiro (UFRJ) - Rio de Janeiro, RJ - Brasil. Professora Universidade do Estado do Rio de Janeiro (UERJ). Rio de Janeiro, RJ - Brasil. E-mail:

conceicaofseixas@gmail.com
}

Submetido em: 07/05/2017 - Aceito em: 23/03/2018

(C) ETD-Educação Temática Digital $\quad$ Campinas, SP $\quad$ v.20 $\quad$ n.3 $\quad$ p.761-780 jul./set. 2018


when no fieldwork is involved, or in what the systematized knowledge by humanity already offers us as a perspective, or in what we inaugurate with our own thinking. To think in this sense is an ethical action, in so far as it implies the other and the adoption of a position with respect to this other. Who is the other-child for childhood researchers? What ethical implications are necessary when we put ourselves to think about childhood? Why think of childhood? For what purpose? What is the place of children in the theory we produce about them? In this paper, we pursue these questions based on the tension that exists between participation and guardianship, protection and authorship. In addition we will reflect on experiences of alterity between children and adults in social life that are put in check in the theoretical make, since theorizing implies not only describing the social world, but also reinstating it.

KEYWORDS: Childhood. Ethic. Participation of children. Protection.

\section{RESUMEN}

El debate sobre la ética en la investigación en Ciencias Humanas, particularmente en la investigación con niños y niñas, es un asunto candente en el contexto brasileño. Esta problemática junto a la de las condiciones de interlocución del investigador con los sujetos que participarán de su investigación han ocupado un papel central. Frente a estas cuestiones, nuestro propósito es traer al centro del debate la dimensión ética que está presente en la propia teoría como un hacer ético. Consideramos que la investigación en Ciencias Humanas siempre implica un Otro, incluso cuando no se haya previsto un trabajo de campo. El Otro está incrustado en la teoría, tanto desde la perspectiva del conocimiento sistematizado por la humanidad que se nos ofrece como punto de partida, como en aquello que inauguramos con nuestro propio pensar. Pensar, en este sentido, es un hacer ético, en la medida en que implica un Otro y un posicionamiento sobre este Otro. ¿Quién es el otro-niño para el investigador de la infancia? ¿Qué implicaciones éticas se imponen cuando nos disponemos a pensar la infancia? ¿Por qué pensar la infancia? ¿Para qué? ¿Cuál es el lugar de las niñas y los niños en la teoría que producimos sobre ellos? En este artículo vamos a abordar estas indagaciones a partir de la tensión que se da entre participación y tutela, protección y autoría, experiencias de alteridad entre niños, niñas y adultos en la vida social, que ponen en jaque el hacer teórico dado que teorizar no implica sólo describir el mundo social sino también instaurarlo.

PALABRAS CLAVE: Infancia. Ética. Participación de los Niños. Protección.

\section{INTRODUÇÃO}

Nossa proposta tem como objetivo apresentar reflexões e análises que contemplam as concepções de infância como uma constante construção de sentidos. Toda construção teórica acerca da infância explicita uma ética, na medida em que implica um posicionamento político em relação às crianças e ao lugar social que elas ocupam na sociedade e na produção do conhecimento científico. Esse lugar, no nosso entender, é um cenário de aporias onde participação, autoria, proteção e tutela disputam sentidos ao que temos concebido como infância. Nossa preocupação se volta para refletir sobre o lugar que as crianças ocupam e como entram nessa disputa de sentidos.

As conquistas em torno da proteção da criança, representadas principalmente pelos marcos legais, são de extrema importância no contexto histórico. No entanto, quando a lógica da proteção se sustenta basicamente na ideia de menoridade, incapacidade, irracionalidade das crianças em relação aos adultos, traz também consigo o risco da tutela e subordinação daqueles/as que devem ser protegidos/as e, consequentemente, o silenciamento de suas falas. A ideia da participação da criança, isto é, considerá-la de fato

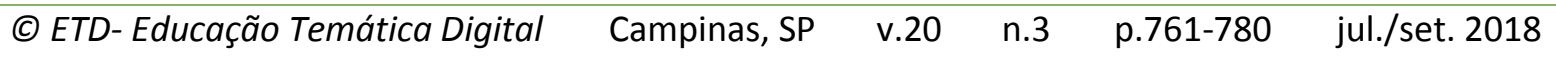


como parte de um todo maior vem acompanhada da aposta de que a criança tem algo a dizer sobre si e sobre o mundo que a cerca. Isso implica na possibilidade de inserção da criança na disputa da produção de uma narrativa sobre sua própria infância.

São muitos os desafios que se colocam nessa produção: como garantir uma proteção das crianças - compromisso geracional que se faz necessário, além de ainda ser desigual sem que isso signifique tutelá-las, mas, ao contrário, abra espaço para a sua participação e autoria? Como equilibrar as noções de proteção e participação que, por vezes, se contrapõem e se atravessam? A participação das crianças não é algo novo ou trivial, mas seus modos são variados, e se conformam de acordo com idades, espaços - público e privado -, questões de gênero, religião, classe social, raça e/ou etnia.

Atualmente o tema da participação da criança torna-se crescente em muitas pesquisas e marcos legais destinados à infância. No entanto, convém problematizar como essa participação se dá nos diversos âmbitos da nossa sociedade, e se é encaminhada de modo a abrir espaço para autoria das crianças. Há que se considerar a desigualdade estrutural que demarca a relação entre crianças e adultos na sociedade e que se torna fundamental para a reflexão que aqui propomos, pois, no que se refere à produção do conhecimento científico, são os adultos que não apenas o produzem, mas são os que o referendam.

Ponderando que não há nas teorias a ingenuidade de se oferecer uma pueril descrição do mundo, o que está posto em jogo com as mais diferentes concepções teóricas sobre a infância são proposições de mundos sociais e de modos de viver a infância. Portanto, a questão não é apenas a participação, mas um conjunto de regras e valores determinados para as crianças e para seus modos de discernir, os quais, por vezes, se tornam pré-requisitos para a essa geração. Acreditamos que os desafios de uma teoria sobre a infância estão fortemente atrelados a uma dimensão ética. Assim, alguns questionamentos se fazem necessários: que normatividades uma teoria sobre a infância põe em cena? Em que medida pode escapar a isso? Que ética está posta em cada teorização sobre a infância? Como a dimensão ética é capaz de abarcar a diversidade, complexidade e alteridade da infância?

\section{TEORIZAR COMO QUEM CRIA MUNDOS SOCIAIS}

Sendo o propósito principal deste texto problematizar o lugar da teoria no debate sobre a ética na pesquisa parece-nos prudente indagar sobre ao que temos nomeado como "teoria" e como "ética" no contexto da pesquisa acadêmica no campo dos estudos da infância - envolvendo tanto os projetos institucionais, quanto as teses, dissertações e

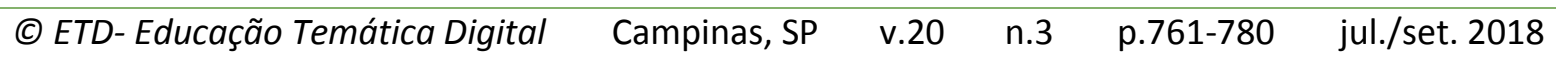


monografias produzidas. Certamente uma pesquisa especificamente construída com o propósito de cercar essa indagação nos forneceria elementos mais precisos para ancorar este debate. No entanto, como aqui a intenção é, justamente, instaurar essa indagação, o chão em que fincamos essa problematização é circunscrito pela nossa experiência de professoras e pesquisadoras que no cotidiano lidam com a produção e a leitura de textos acadêmicos ligados à temática da infância, sendo que nosso olhar se ancora, principalmente, nos postulados de Mikhail Bakhtin (2003, 2010), Marilia Amorim (2000) e Walter Benjamin (1987) acerca das ciências humanas.

Nossa experiência parece indicar que, de um modo geral, a "teoria" mais fortemente vem sendo concebida nos limites do que seja uma "revisão de literatura", isto é, a parte do texto em que os autores se dedicam a apresentar as leituras já feitas sobre o tema. Outras partes do texto como, por exemplo, a apresentação do campo da pesquisa, o detalhamento da metodologia, a apresentação dos interlocutores, as análises etc. muitas vezes são trazidas não apenas de forma apartada da revisão de literatura já feita, como também esses enunciados são apresentados de forma unicamente descritiva. Mesmo as conclusões dos textos, em grande medida, não ocupam o papel (autoral) de uma teorização, limitando-se a uma reafirmação descritiva dos "achados empíricos". É como se os pesquisadores reconhecessem nas leituras feitas - sobretudo na leitura dos autores clássicos - a existência de uma teoria, enquanto o texto que eles estão a escrever, não fosse, ele mesmo, enquanto texto de pesquisa, um lugar de teorização. Isso nos convida a uma primeira provocação: Os pesquisadores da infância reconhecem-se como teóricos da infância? Assumem essa tarefa? Abdicam desse papel? Em que medida a concepção do que seja "teoria" é definidora da construção desse lugar social? E ainda, em que medida uma revisão de literatura é, em si, uma teorização?

Na mesma direção, vale lançar um olhar sobre o que temos chamado de "ética na pesquisa". É ter em mãos as autorizações dos responsáveis? É decidir se menciona ou não o nome das crianças? É conhecer a legislação vigente para saber o que pode ou não pode fazer? O que estamos chamando de "ética na pesquisa"? Quais as indagações que envolvem a teoria? Em que medida as formas como indagamos e respondemos a isso têm sido incluídas nos textos resultantes das pesquisas?

De um modo geral, não temos percebido que esse tema - como tema a ser problematizado - venha merecendo destaque nos textos de pesquisa. É sim, cada vez mais frequente, uma descrição das decisões tomadas pelo pesquisador em relação aos procedimentos metodológicos, sem necessariamente apresentar essas decisões como constituintes da produção de uma ética de pesquisa, de uma ética que só pode ser pensada no contexto específico daquela pesquisa, porque responde a questões que são próprias $\begin{array}{llllll}\text { (C) ETD-Educação Temática Digital } & \text { Campinas, SP } & \text { v.20 } & \text { n.3 } & \text { p.761-780 } & \text { jul./set. } 2018\end{array}$ 
daquela pesquisa. Mais uma vez, parece-nos importante retomar as provocações iniciais: Os pesquisadores da infância reconhecem-se como produtores de uma ética de pesquisa? Assumem essa tarefa? Abdicam desse papel? Em que medida a concepção do que seja "ética" é definidora da construção desse lugar social?

Feitas estas questões, para problematizarmos o lugar da teoria no debate sobre ética em pesquisa talvez nos seja necessário lançar um olhar que permita ver quais pormenores da atividade pesquisa são focados na definição do que seja uma ética e que outros aspectos acabam secundarizados ou mesmo negligenciados. Nossa experiência de trabalho tem sugerido que as preocupações que estão em pauta quando se trata de uma ética de pesquisa, no campo das ciências humanas e sociais, tem se voltado mais especificamente para o contrato que normatizará o encontro do pesquisador com os sujeitos que participarão da sua pesquisa e as condutas que balizarão esse diálogo, sobretudo a concordância de participação na pesquisa (por parte dos sujeitos) e o compromisso de não exposição desses sujeitos (por parte do pesquisador). É como se a construção desse contrato se constituísse como uma das etapas da pesquisa, como uma antessala para o trabalho de campo. A construção desse contrato têm sido o objeto central dos diferentes Comitês institucionais de pesquisa, nos mais distintos campos disciplinares. É como se os pesquisadores, ao terem em mãos os documentos que firmam esse contrato, pudessem considerar cumprida essa "etapa" da pesquisa relativa às questões da ética.

Tal procedimento sugere que o lugar da alteridade na atividade de pesquisa fica mais visível no trabalho de campo. E não por acaso, muitas vezes o que vemos nomeado como sendo "a pesquisa" é a parte que se refere especificamente ao trabalho de campo. O que essas práticas têm nos levado a suspeitar é que a teoria, e, mais especificamente, a teoria no contexto do debate sobre a ética na pesquisa têm se mostrado secundarizada. Dois aspectos nos levam a essa suspeição: um primeiro, quando o que no texto é tratado como teoria se reduz a uma revisão de literatura sobre o tema da infância que é trazida de forma historicamente linear e evolutiva e nem sempre amalgamada ao tema específico do estudo (independendo se é o brincar, a mídia, as políticas de educação infantil, o abandono, a adoção, as migrações, por exemplo). É como se essa "evolução conceitual" garantisse ao pesquisador uma filiação ao que há de mais atual no debate sobre infância. O segundo aspecto diz respeito ao fato de que o pesquisador nem sempre se coloca no lugar de quem precisa entrar na corrente dialógica instaurada pela revisão de literatura que fez, isto é, o pesquisador parece conduzir o seu trabalho sem que este seja, para ele, uma indagação ou uma forma de responder às questões de sua pesquisa. Dito de modo simples, traz os autores lidos para dialogar com seu trabalho, mas não chega a conversar com eles problematizar seus conceitos, duvidar do que é dito, superar alguns dilemas, instituir

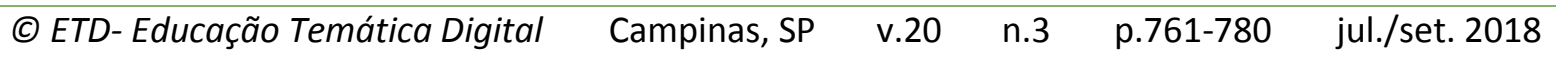


outros. É como se o que chama de teoria fosse algo unicamente a ser "citado" e não questionado, produzido, criado.

Não podemos negligenciar deixando de abrir aqui um parêntese para invocar uma série de indagações, não de menor importância, mas que não são exatamente o foco da reflexão a que nos propomos. Na história da produção social do conhecimento, quem está "autorizado" a teorizar? Em que condições é produzida essa "autorização"? Como os diferentes campos disciplinares negociam essa autorização? Pode o aluno de graduação, o mestrando, o doutorando, o pesquisador "teorizar"? O que reconhecemos como teoria? Que dualismos, maniqueísmos e hierarquias construímos em torno da relação entre "teoria" e "empiria" e, mais fortemente no campo da educação, entre a "teoria" e as "práticas"? Que instâncias definem o que seja um agir ético em pesquisa? Que procedimentos estão vinculados a esse agir? Que instituições e campos disciplinares disputam a "autoridade" de dizer o que seja ética em pesquisa? Como esses discursos sobre "teoria" e sobre "ética" formam, formatam, conformam, deformam o ato de pesquisar? Em que medida estas perguntas são perguntas de um pesquisador? Fecha parênteses.

Proporemos aqui um caminho de discussão acerca dos conceitos de "teoria" e de "ética" visando a elaboração da tese que buscamos compartilhar: a de que a construção teórica de uma pesquisa é, em si, um agir ético. Para tanto, recorreremos, inicialmente, à própria etimologia da palavra "teoria", recurso bastante potente quando as palavras se esgarçam a ponto de já não parecerem suficientes para dizer. Nosso propósito é trazer aqui a palavra teoria da maneira mais horizontalmente possível, para que ela possa banhar-se de sentido com o hálito do debate, como uma palavra que trata de uma produção humana, portanto, possível a todos e em todos os campos de conhecimento.

Derivada da palavra grega theoreîn um dos significados da palavra teoria é o "olhar através de", isto é, não uma narrativa direta sobre as coisas, mas uma narrativa que é mediada, marcada pelas nuances daquilo através do que se olha. Originariamente lapidada no contexto do teatro, dos jogos e das festas, o theorós era o espectador, aquele que via "através do teatro", "através dos jogos", "através da festa". Retomar essa perspectiva nos parece importante porque provoca um deslocamento de lugares. Repare que o teatro, por exemplo, implica a fusão de elementos como o texto, o autor do texto, os atores etc., mas não é nenhum deles o "tehorós" e, sim, quem vê através do teatro, o seu espectador. E o que via o "tehorós" através do teatro, através dos jogos ou através das festas? A justiça, a luta, a alegria, a morte, a beleza, a verdade. A teoria seria, então, o que o tehorós, tendo visto "através de", pode, então, dizer daquilo que viu. A teoria é aquilo que se torna referência, aquilo que referencia, a partir de então, o nosso olhar.

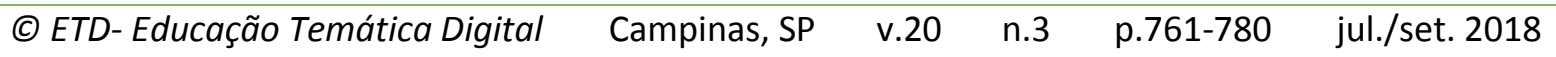


Esse jogo entre "o que está lá para ser visto", "o que vemos", "o modo como vemos" e o que "dizemos" daquilo que vemos é o que constitui a teoria. A teoria é a visão construída através dessas artes e dos conhecimentos. O que foi "visto" não existe sem as artes que permitiram ver. Dito de outro modo, o conteúdo não existe sem a forma que permitiu a sua existência. Assim, o que caracteriza a natureza da teoria é o modo como ela propõe e/ou apresenta uma visão sobre o mundo. Uma visão que é construída sob critérios de sistematização. A arte tem seus critérios. 0 jogo tem seus critérios. A festa tem seus critérios. A ciência tem também os seus critérios. E esses distintos critérios se alteram conforme os tempos históricos, as culturas, as sociedades e as relações de poder.

Uma teoria sobre a infância é, em primeira instância, um olhar para a infância através das artes, das ciências, das políticas e dos saberes acumulados pela cultura. E aqui reside a diferença entre a teoria e o reino da opinião (a doxa): a teoria não nasce do olhar afoito que se autoriza a dizer sobre as coisas antes mesmo de conhece-las e de saber se sobre elas a humanidade já se pronunciou. A teoria exige um "tornar-se pequeno" em face da cultura para poder dela se aproximar, exige a experimentação de diferentes ângulos através dos quais se possa olhar, exige uma adesão aos modos de ver que respondem às indagações que nos movem, exige sabedoria para problematizar, recusar, superar os modos de ver e as verdades às quais não aderimos. A teoria implica simultaneamente uma revisão do já existente para a construção singular de nossas referências e uma recriação através destas. Por isso a teoria é também um posicionamento. É um agir, no dizer de Bakhtin (2003).

O que nos faz pensar ou não sobre um tema, uma situação, uma problemática da vida, já é um posicionamento no mundo. E o nosso pensar, ao criar narrativas sobre o mundo, cria também novas demandas. Por isso, uma teoria sobre a infância é também uma narrativa implicada em dizer "que é a infância" e, nesse sentido, produz a infância, produz as realidades em que a infância "deve" se constituir. Participação, proteção, tutela e autoria são aspectos que nos ajudam a explicitar o agir ético que está na base de qualquer construção teórica acerca da infância. Toda teoria sobre a infância reserva um lugar ou um não lugar para a infância. E essa alteridade que se efetiva na teoria é decisiva para a escolha do campo de pesquisa (a escola, a casa, a rua, as redes sociais etc.), para as formas de interlocução com as crianças, para a tradução do campo em texto, enfim, para os contratos institucionais envolvidos etc.

Com este caminho procuramos tornar visível o quanto a teoria é, ela mesma, um agir, prenhe de escolhas e posicionamentos, e, justamente por essa razão, dotada ou exigente de uma ética. Há uma ética na construção teórica. E essa ética é crucial para a pesquisa. A alteridade numa pesquisa não se instaura no encontro do pesquisador com seus

$\begin{array}{llllll}\text { (C) ETD-Educação Temática Digital } & \text { Campinas, SP } & \text { v.20 } & \text { n.3 } & \text { p.761-780 } & \text { jul./set. } 2018\end{array}$


sujeitos naquilo que seria o trabalho de campo (uma pesquisa unicamente teórica, então, não implicaria um debate sobre ética?). A ética de uma pesquisa se instaura na escolha de um tema (e na recusa de outros), no recorte que dá centralidade a alguns aspectos (e torna invisíveis outros) nas formas que escolhemos para trata-los, nos olhares e nas vozes que autorizamos participar do debate (e naqueles que calamos ou colonizamos), enfim, no teor daquilo que dizemos.

Que realidades estamos a criar quando nos colocamos a teorizar sobre a infância? Que questões se colocam em pauta e como nos posicionamos frente a elas? Qual é o auditório social que temos em mente quando escrevemos nossos textos? Com quem (e para quem) estamos a dialogar? Questões como estas trazem para o centro do debate a dimensão ética que atravessa a tarefa dos intelectuais na produção social do conhecimento, aqui pensado mais amiúde nos limites do campo dos estudos da infância. É a alteridade constitutiva da teoria que queremos colocar em cena a fim de problematizar a dimensão ética que atravessa o teorizar sobre a infância. Para tanto, escolhemos por caminho deixar emergir os conflitos que no campo dos estudos da infância nos instigam a indagar quem são as crianças nas teorias sobre a infância e que infâncias estamos a produzir com as teorias que criamos. Concepções de proteção, participação, tutela e autoria ajudam-nos a dar visibilidade à ética que silenciosamente habita as teorias sobre a infância, posto que teorizar é um ato de construção de mundos sociais em que se desenham lugares ou deslugares para as crianças e suas infâncias.

\section{O DESAFIO DA PARTICIPAÇÃO E A PROBLEMÁTICA DA AUTORIA DA INFÂNCIA NA SOCIEDADE}

Como afirmamos, a ética atravessa tanto a investigação empírica quanto a construção teórica e exige do pesquisador diferentes e novos olhares no tratamento, na escuta e no modo de se relacionar com as crianças e a infância. A dimensão ética engendra inúmeras questões epistemológicas, pois há uma complexa e ambígua relação e interação entre adultos-crianças, proteção-participação, tutela-autoria e dependência-poder que produz uma rede de constantes tensões entre verdades produzidas e atuações desconsideradas. É nesse enredo do agir ético que se constitui um quadro teórico, metodológico e histórico que se organiza a partir de diferentes questões: $O$ que as crianças e a infância têm de importante a dizer? De que forma e em que contextos e circunstâncias seus direitos, suas falas e suas ações são reconhecidas? Quais são os espaços sociopolíticos das crianças e da infância? O que queremos afirmar é que, mesmo que os meandros do processo sejam complexos e ambíguos, a pesquisa e a produção teórica permitem o reconhecimento das crianças e da infância, o qual revela suas identidades, suas ideias e suas posições sociopolíticas, isso inclui reconhecer as formas de participação da infância e a

$\begin{array}{llllll}\text { (C) ETD-Educação Temática Digital } & \text { Campinas, SP } & \text { v.20 } & \text { n.3 } & \text { p.761-780 } & \text { jul./set. } 2018\end{array}$


condição das crianças como atores sociais. Afinal, por um lado, as pesquisas com, sobre e das crianças e infância constroem conceitos a respeito dos seus modos de ser, referendam seus espaços e tempos, permitem que seus discursos e ideias sejam repercutidos e ainda as colocam como participantes na investigação. Por outro lado, as pesquisas também revelam as relações de poder entre adultos e crianças que podem limitar, escamotear ou restringir a participação delas, dos seus dizeres, das suas ações e como a infância quer ser percebida na e pela sociedade. Portanto, os saberes científicos produzem novos dispositivos sociopolíticos.

Partimos do pressuposto de que a pesquisa que reconhece as crianças e a infância como atuantes e participantes nos seus espaços e tempos é aquela que estabelece uma simetria ética - conforme sustentam Christensen e Prout (2002) - e constrói uma narrativa da infância. Para tanto, o pesquisador deve empregar, de acordo com as situações concretas, os mesmos princípios éticos, uma simetria no tratamento quer sejam crianças, jovens, adultos ou velhos. Tratar dos princípios éticos na pesquisa com as crianças significa considerar a alteridade da infância, reconhecer que elas são sujeitos de direitos e produtoras das suas histórias, e compreender a forma sutil, porém complexa e profunda, de como a infância reflete a sociedade e se faz nela. Desta forma, é preciso que as crianças tenham ciência de que participam de uma investigação e que elas podem se recusar a participar, podem ter liberdade para desistirem a qualquer tempo e que serão respeitadas nas suas especificidades e no seu direito à informação - entre eles dos resultados da pesquisa da qual participaram. De outro modo, a reflexão teórica acerca da infância implica em uma construção abstrata que busca e compreender fatos, apreender as causas, desnaturalizar conceitos e explicar uma grande variedade de situações empíricas (GIDDENS, 1988). Com razão, são novas abordagens metodológicas e teóricas que destacam a coprodução entre pesquisador e crianças (CHRISTENSEN, PROUT, 2002). De todo modo, diante da participação e autoria das crianças e da infância, surgem indagações tratadas inicialmente a respeito do diálogo e das formas de documentar aquilo que foi construído, por exemplo, entre o pesquisador e os bebês, as crianças pequenininhas, as crianças pequenas, as crianças grandes e os adolescentes. Além disso, ainda há um embaraço ao retornar os resultados de uma investigação que em geral se apresenta em linguagem acadêmica.

A problemática da participação e da autoria é uma questão ética que se dá ao passo que a infância é reconhecida como um fenômeno social a ser teorizado e as falas e práticas das crianças a serem indagadas e investigadas. Em outras palavras, passamos a teorizar o fenômeno da infância, porque passamos a reconhecer, problematizar, questionar e rever as suas manifestações, as formas como participam da sociedade e como são valorizadas as

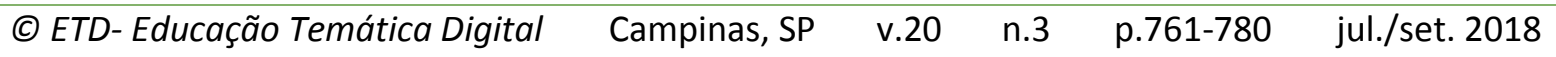


ideias e atitudes tomadas pelas crianças. Qvortrup (2002) afirma que na atualidade o maior interesse da comunidade científica em relação à infância e às crianças é decorrente do fato de que elas passaram a ser consideradas um problema social. Para Mayall (2007), existem três razões para esse interesse nas crianças. Primeiramente, aprimorar o conceito relativo ao funcionamento da sociedade. Em segundo lugar, ter uma justiça social para elas. Enfim, refletir sobre os fundamentos teóricos em relação aos serviços para a infância. De todo modo, queiram ou não, as crianças ao nascerem são inseridas na infância, recebem influência das determinações biopsicosocial e influenciam seus espaços e tempos sociais conforme atuam e participam.

A infância é um fato que deve ser (re)conhecido porque é efetiva e atuante, é parte integrante e essencial da/na sociedade, tem permanência, poder, coerções e sanções, tem posição e função social. Ademais, a participação das crianças na sociedade não é algo trivial, ao contrário disso, elas participam de forma organizada das atividades, as quais estão integradas às dos jovens, adultos e velhos e que são instrumentalmente usadas pelo conjunto social (QVORTRUP, 1990). Isso significa que não há um momento estabelecido socialmente para a participação das crianças nos seus espaços e tempos, elas fazem isso continuamente e desde que nascem.

Porém, esse reconhecimento da participação da infância ainda está sendo aos poucos construído social e culturalmente, tanto no cotidiano quanto nos âmbitos das investigações científicas, visto que as crianças são sujeitos de direito e, portanto, com direito a pelo menos conhecer o que se quer delas. Afinal, as pesquisas ainda nos levam aos questionamentos sobre: Quais são as formas de participação da infância na sociedade? 0 que significa as crianças participarem da sociedade? Como devem participar? Como realizar uma investigação com crianças de forma ética, com o real consentimento delas e que revele os modos de participação da infância? Como tomá-las como sujeito da pesquisa? Como legitimar a autoria das crianças e as ações da infância?

A participação é um assunto controverso porque traz à tona o embate entre a ideia de que as crianças são irresponsáveis, irracionais e incapazes de fazerem suas escolhas, de serem informadas em assuntos que the dizem respeito e de darem informações, em contraposição ao seu reconhecimento como atores sociais, indivíduos de capacidade, de ação e de conhecimento (SOARES, 2005). O conflito se dá entre a negação das capacidades das crianças, o empoderamento e a cidadania delas. Além disso, a dimensão da participação assume contornos incertos conforme o espaço, público ou privado, e a relação com outros sujeitos ainda ocorre em nome do que seria o melhor para a criança, sendo que em geral quem decide isso é o adulto.

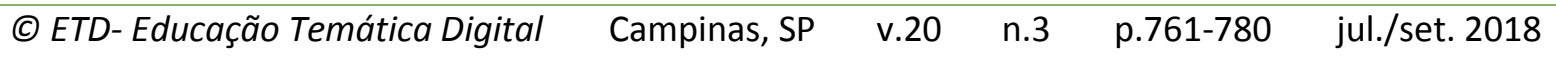


Esses embates, que permeiam muitas decisões da pesquisa, se tornam manifestos a partir de leis e diretrizes que consagram um conjunto de direitos que abrangem a participação da infância na sociedade. No caso brasileiro, a Constituição Federal (BRASIL, 1988), a ratificação da Convenção Internacional sobre os Direitos da Criança (BRASIL, 1990a), o Estatuto da Criança e do Adolescente (BRASIL, 1990b), complementado pelo recém sancionado Marco Legal da Primeira Infância (BRASIL, 2016), consideram a criança sujeito social de até 12 anos de idade incompletos - como cidadã e a participação um direito de toda criança desde seu nascimento. Podemos interpretar que esse conjunto de leis garante - pelo menos no papel - uma cidadania às crianças. Mas, por outro lado, temos comissões de pesquisa que regulam as formas de realizar a pesquisa com as crianças e a infância. Sendo assim, em que medida, ao ouvirmos as crianças e entendermos suas práticas isso garante benefícios para elas e uma postura ética com elas? Os resultados das decisões públicas ou privadas são moldados ou impactados a partir do resultado da participação delas? (GRAHAM, FITZGERALD, 2010).

No nosso entender participar se refere a tomar decisões nas atividades coletivas, significa decidir e fazer, considerando que esse envolvimento das crianças faz a diferença e acaba por modificar de alguma a forma como a sociedade as percebem. Porém, é um jogo de forças e resistências delas com jovens, adultos e velhos, que tratam a participação como escuta ou apenas consulta (THOMAS, 2007). Assim, deixam de ser consideradas suas decisões, seus fazeres, suas ideias e suas necessidades.

Na verdade, pouco se conhece dos modos de participação e das ações da infância e das crianças na sociedade. Sgritta (1997) pondera que esse precário conhecimento decorre da condição da infância e das crianças na sociedade ser de segunda ordem, pois as crianças ainda são consideradas menores e não cidadãs, não são titulares dos seus direitos, não têm representação direta nas instâncias sociais e são consideradas de domínio de um adulto. De acordo com o Sgritta, os direitos da infância representados pelos "3-P" - proteção, participação e provisão - são de uma série $B$, pois só quando as crianças se tornam adultos é que passam a ter direitos de um cidadão de fato (Id.).

Bem, não cabe aqui discutir quais devem ser as competências dos indivíduos para a participação na sociedade, mas sabemos que para participar da sociedade não é prérequisito ou tampouco obrigatório ser competente ou experiente (QVORTRUP, 2011). E por serem titulares de segunda ordem as crianças ainda têm poucos representantes na sociedade e/ou quase sempre são representadas apenas por aqueles que têm filhos/as ou que de alguma forma estão comprometidos com a infância.

$\begin{array}{llllll}\text { (C) ETD-Educação Temática Digital } & \text { Campinas, SP } & \text { v.20 } & \text { n.3 } & \text { p.761-780 } & \text { jul./set. } 2018\end{array}$


É nesse sentido que se pode afirmar que ainda subjugamos a infância, consideramos as crianças cidadãs de segunda ordem e igualmente vulneráveis na estrutura, diante da deficiência de poder político, econômico, social e civil dirigidos a elas. O que se vê é que os meios, os recursos, as influências e o poder são distribuídos de maneira desigual entre as categorias geracionais, cujas disposições para enfrentar os desafios externos são diferentes (SGRITTA, SAPORITI, 1989). E a vulnerabilidade estrutural dada à infância é própria de uma construção histórica, social e política, e de presunções a respeito da natureza da infância estabelecidas por atitudes culturais (LANSDOWN, 1994). Por sua vez, a ideia da incapacidade das crianças acaba por protelar o exercício da autonomia à participação e acaba por não afirmar autoria delas, como indivíduos do mundo, atuantes, atores sociais e coprodutoras da sociedade e da infância.

A participação e autoria da infância e das crianças ainda se revela por meio de um adulto vinculado a elas que na maioria dos casos são seus pais e/ou professores/as - e agora também os/as pesquisadores/as. Em geral, se lhes é dada alguma autonomia e possibilidade de participação, essa também depende da definição estabelecida pelos adultos, uma definição que abrange concepções políticas, éticas e epistemológicas e, no caso da pesquisa, abrange implicações metodológicas, as quais veem sendo questionadas, de um modo ainda circunscrito. Agora, se fosse garantido o reconhecimento da sua autoria e uma participação ativa com o envolvimento direto das crianças no decidir-fazer, na produção de suas narrativas e uma posição ética em relação aos sujeitos da pesquisa e do agir cotidiano, talvez fossem constituídas outras ações, práticas e outros discursos acerca da infância. A participação das crianças na sociedade se faz da confirmação e realização dos direitos delas, fornece responsabilidades legais, amplifica suas habilidades, aprimora os serviços destinados à infância, amplia o processo democrático, promove a proteção e as empodera (THOMAS, 2007).

Como se vê a questão da participação e autoria é delicada, complexa e profunda pois envolve sujeitos com interesses e poderes diversos. Portanto, é preciso tratar de forma ética a infância de modo a proteger as crianças, mas é preciso também legitimá-las como sujeitos de direitos, com possibilidades de autoria e participação. Construir olhares diferentes para o grupo social da infância - bebês, crianças bem pequenas, pequenas e grandes - significa viabilizar e discutir seus direitos de produzir conhecimento, abrir portas para ampliar e amplificar concepções de infância que incluam, também, as ideias de infância das próprias crianças, as quais podem aportar uma visão diferenciada de mundo (BARBOSA, 2014). Mundo este que, certamente, será diferente.

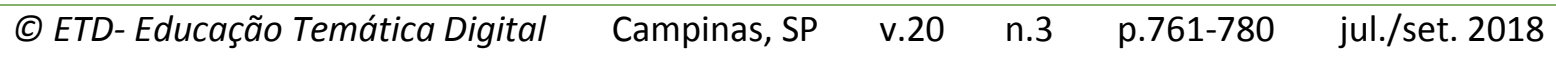




\section{3 Quando a lógica da proteção implica o silenciamento das crianças}

Toda construção teórica acerca da infância explicita uma ética, assim como delineia o sentido de participação que se espera das crianças em diversos âmbitos da nossa sociedade - incluindo as pesquisas que se fazem delas e com elas -, e a forma como os adultos entendem como devem protegê-las. As concepções de infância presentes no nosso cotidiano e nos conhecimentos científicos estão relacionadas a uma série de disputas de sentidos, entre os quais se destacam as noções de proteção e tutela. Neste tópico, é do nosso interesse, ao problematizar a lógica da proteção, refletir sobre o lugar que a criança ocupa nas teorizações que se fazem delas e como entra nessa disputa de sentidos.

As conquistas em torno da proteção da criança, representadas principalmente pelos marcos legais, são sem dúvida um avanço no contexto histórico e nas lutas políticas relacionadas ao campo da infância. Além disso, essas conquistas se inscrevem no compromisso que as gerações mais velhas têm com as gerações mais novas. No entanto, quando a lógica da proteção se sustenta basicamente na ideia da menoridade, incapacidade, irracionalidade das crianças em relação aos adultos, traz também consigo o risco da tutela e subordinação daqueles/as que devem ser protegidos/as e, consequentemente, o silenciamento de suas falas. Um dos fios da navalha que trataremos neste trabalho reside exatamente nessa linha tênue que pode ser traçada em torno da noção de proteção, que, como disputa de sentido, pode significar cuidado - em uma dimensão ética e política de resposta e endereçamento ao outro (MATTOS et al., 2013) -, como também tutela. Assim, convém problematizar a noção de proteção que, muitas vezes, parece inquestionável, de modo que evitamos enfrentar o que de paradoxal pode conter nessa noção e de nos perguntar: o que implica proteger as crianças? Que relação ética estabelecemos com as crianças ao produzirmos o discurso da proteção - um que se abre para acolher sua fala ou que estabelece com elas uma relação de tutela? A ideia da proteção está apoiada em que construções teóricas sobre a infância?

Se admitimos, conforme abordamos acima, que a produção de teorias sobre a infância não resulta apenas da leitura de como a "infância é", mas, ao mesmo tempo, aponta para caminhos de como "a infância deve ser", podemos supor que isso acarretará em consequências para o modo como as crianças vivem suas infâncias e também como nós adultos nos relacionamos com elas. Uma das consequências da forma de narrar a infância com características como imaturidade, incompletude, irracionalidade, despreparo é o credenciamento daqueles que supostamente são racionais, preparados, completos (os adultos) como alguém que pode falar pelas crianças e assumir sua tutela. Nesse contexto, lembra Castro (2011) que crianças ficam de fora do direito a serem reconhecidas como seres falantes, no sentido público do termo fala, como aquela que é considerada em suas $\begin{array}{llllll}\text { (C) ETD- Educação Temática Digital } & \text { Campinas, SP } & \text { v.20 } & \text { n.3 } & \text { p.761-780 } & \text { jul./set. } 2018\end{array}$ 
demandas nas decisões da vida em comum. Essa lógica tutelar é o que endossa, segundo a autora (Idem), de um lado, a exclusão simbólica da criança de vários âmbitos sociais e, de outro, a representação de seus interesses nos espaços de tomadas de decisão pública - por que não nas pesquisas elaboradas pelos adultos? -, retirando da criança o direito de falar por si própria, ser também autora das narrativas que se produzem sobre suas infâncias, agir no mundo como sujeito político.

Outro aspecto da representação, visto como problemático por Young (2006), é o fato de o indivíduo ou grupo que representa se colocar em uma relação especular com os representados. Quando representamos as crianças no espaço público ou em pesquisas, muitas vezes, tratamos de nossas demandas, desejos e expectativas como se fossem as delas. Não é raro observarmos situações em que crianças questionam nossas decisões e respondemos com frases do tipo: "eu sei o que é melhor pra você"; "quando você crescer, você vai entender", ainda que crescidos não entendamos uma série de decisões tomadas em nossos nomes. Assim, Castro (2011) e Young (2006), ao questionar a lógica da representação, estão chamando atenção para o silenciamento e invisibilização política que podem acompanhar $\mathrm{o}$ ato de representar, para a postura paternalista contida na ideia de "eu sei o que o outro precisa", além de distanciar a criança da possibilidade de participar propositivamente da vida social e das narrativas que são produzidas sobre ela.

Ao problematizar as disputas em torno do sentido da proteção destinado à criança, não significa esquecer da sua necessidade de cuidado e do nosso compromisso geracional, enquanto adultos, mas pontuar a diferença entre a responsabilidade dos mais velhos e a tentativa de controlar e silenciar os mais novos. Imbuídas dessa ideia, dizemos que proteção não pode ser sinônimo de silenciamento. Nesse sentido, a grande tarefa - nada fácil - que se coloca para todos nós, principalmente pesquisadores da área da infância, é: como garantir espaços de fala pública a crianças sem negligenciar sua necessidade cuidado? Como afiançar o direito ao cuidado e à proteção da criança sem intervir no seu direito de falar, participar, ser autora? Como sustentar a lógica da participação das crianças sem que isso incorra no discurso da redução da maioridade penal? Ou seja, como pensar na lógica de participação e igualdade das crianças em relação ao adulto sem que isso implique tomá-las como adultos, e sem que também implique na não responsabilidade ou descompromisso ético das gerações mais velhas em relação às gerações mais novas.

No bojo da problematização do discurso da proteção, e levando em consideração que a ideia de proteção vem acompanhada da retirada das crianças dos âmbitos sociais amplos e do seu confinamento nos espaços privados de preparação, Qvortrup (2015) pergunta quem paga os custos dessa exclusão? Não seriam as crianças, em favor de protegê-las do caos e perigo urbano, por exemplo, que são retiradas do convívio nos

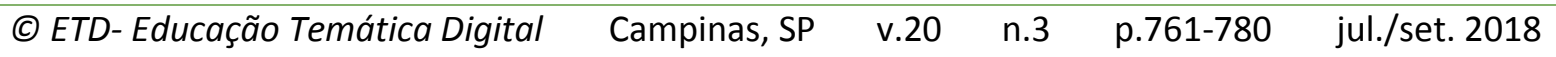


espaços públicos e que têm seu direito de ir e vir negado? Não seriam elas, por seu suposto despreparo, que têm seu direito de produzir conhecimento sobre sua própria infância prejudicado?

Não podemos esquecer também que, em se tratando de um país desigual como o nosso, as diversas crianças vivem a lógica da proteção de diferentes maneiras. Algumas crianças são mais destituídas de seus direitos, são mais governadas por uma institucionalidade que visa controlá-las, são mais sujeitas às negligências sociais, educacionais, e mais silenciadas que outras. Outras crianças são bastante ouvidas, inclusive fazendo dos adultos reféns de seus desejos, e não necessariamente por sua culpa, mas devido à configuração social e econômica que as colocam num lugar de alto grau de investimento, de modo que não podem ser contrariadas ou ouvir não. Que ética habita uma teoria quando ela explicita ou inviabiliza essa desigualdade, quando ela se pretende conjuntural ou universalizante?

Pensando nos desafios que se colocam para o tema da proteção, e equilibrando essa noção com a de participação, é que problematizamos o lugar de tutela, de sujeitos que não podem falar por si, que as crianças ainda ocupam em nossa sociedade, e apostamos nos caminhos que possibilitam às crianças falarem, agirem e participarem das teorias que são produzidas sobre elas, serem autoras. Estamos de acordo com Castro (2011) que os dispositivos legais não produzem de modo automático a fala e o agir das crianças, assim como, em situação de pesquisa, o mero contrato que normatiza o encontro do pesquisador com as crianças não da conta dos embates éticos dessa relação. O que temos chamado sobre ética na pesquisa quase sempre se relaciona aos procedimentos que visam a atender à legislação que, ao exigir o consentimento do responsável e mesmo das crianças, a retirada de seus nomes, entre outros procedimentos, tem como objetivo proteger esses indivíduos, não expô-los. Mas, por outro lado, cabe questionar se, em uma pesquisa, esses procedimentos dariam conta de instaurar uma ética entre adultos e crianças que viabilize a fala e a participação das primeiras? Sua participação estaria garantida com o simples ato de consentir? E quando a lógica de proteção anula sua autoria?

Possibilitar canais de fala e escuta das crianças é uma tarefa importante, necessária e uma forma desses indivíduos participarem do mundo que os cerca e das teorias produzidas sobre eles. No entanto, entendemos que a escuta e a fala nem sempre se dão de forma tranquila e fácil, sem ruídos. Numa situação de pesquisa, por exemplo, nem sempre quando se abre um espaço de fala, as crianças vão dizer aquilo que os adultos querem. Nesse sentido, faz-se necessário, como pontua Mattos (2013), estar aberto à alteridade, à diferença e mesmo à recusa desses sujeitos de querer falar. Alguns canais de diálogo, como aqueles supostamente presentes em algumas políticas destinadas às crianças ou em $\begin{array}{llllll}\text { (C) ETD-Educação Temática Digital } & \text { Campinas, SP } & \text { v.20 } & \text { n.3 } & \text { p.761-780 } & \text { jul./set. } 2018\end{array}$ 
algumas pesquisas, falham quando não se abrem para acolher o que elas têm a dizer de fato, que pode ir na contramão do que os especialistas, pesquisadores ou gestores presumem. Para que esses canais venham a ter êxito, há que se abrir para a experiência da criança, para sua singularidade (PEREIRA, 2012). Caso contrário, estabeleceremos, em nossas pesquisas, um mudo diálogo a partir do que supomos o que é a infância. De acordo com esses pressupostos, a pesquisa se encaminha não para o encontro com o novo, mas para confirmar respostas e saberes que se posicionam anteriormente ao ato de pesquisar.

A teoria como visão de mundo, conforme explicitado no primeiro tópico, isto é, como inauguração de um posicionamento e estabelecimento de um lugar de fala, e não como revelação de algo que está posto implica encará-la como uma produção possível a todos e todas, inclusive às crianças, que veem e falam de um lugar, carregam sua visão de mundo. E é na possibilidade da constituição de um espaço de troca, de diálogo, negociações e enfrentamentos entre as diferentes posições, que uma ética que abra espaço para a fala da criança poderia ser fundada. Não é pelo fato da criança ser diferente do adulto que ela seria inapta a contribuir para a teorização sobre sua infância e para outros assuntos que lhe dizem respeito. Pelo contrário, é justamente por ser diferente e, por isso, ter a possibilidade de questionar e perspectivar a visão do adulto como sendo a única possível, que a fala da criança pode inaugurar visões de mundo mais plurais (CASTRO, 2013). E é pelo fato de entendermos que teorias não são apenas dizeres vagos sobre determinadas questões, mas que elas instauram lugares - e, no caso das teorias sobre a infâncias, produzem modos e valores sobre como as infâncias "deveriam" ser e viver -, é que consideramos a importância da fala das crianças no teorizar sobre suas vidas. Dizer que a criança pode e deve participar do mundo que a cerca é considerá-la partícipe junto com as outras categorias geracionais desse mundo, o que implica admitir que a criança - dentro das suas possibilidades - tem algo a dizer sobre si e sobre o mundo que habita, pelo simples fato de fazer parte dele. Implica considera-la, dentro das pesquisas sobre sua infância, autora das teorias que são produzidas sobre e com elas. O que não necessariamente significa tomá-la como pesquisadora, mas que sua fala seja escutada e levada em consideração. Ou, como dissemos, que possamos, em nossas pesquisas, escutá-la de fato e não apenas consultá-la.

\section{A INFÂNCIA NO FIO DA NAVALHA}

Assumir a ética como parte da questão de pesquisa e como balizadora de uma construção teórica nos convoca a ocupar a pesquisa que fazemos de um outro lugar, não daquele que se permite passear desinteressadamente pela literatura acumulada sobre infância, mas daquele que, ao posicionar-se, teoricamente, transforma a infância numa causa, não uma causa no sentido panfletário, mas uma causa para o pensar. Uma causa onde não há inocência nem álibi para o agir. O pesquisador, ao teorizar, estabelece uma

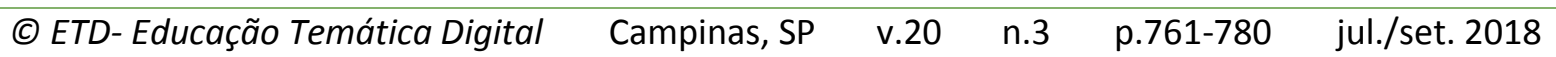


alteridade concreta com a experiência da infância e com as crianças que sua teoria pretende abarcar. O pesquisador ao ter as crianças como participantes de sua pesquisa e atores sociais estabelece uma série de desafios teóricos, empíricos, éticos e morais, entre eles assumir a responsabilidade pelas crianças. Por isso mesmo, aspectos como proteção, participação, tutela e autoria não são apenas temas ou categorias de análise, são realidades teoricamente afirmadas ou negadas, evidenciadas ou invisibilizadas. E essa teorização, por sua vez, será balizadora tanto da participação da criança na pesquisa quanto da realidade social concreta que com nossa pesquisa fazemos existir. É difícil imaginar uma prática e uma teoria que tenha como pressuposto a ética que não coloquem essas questões no centro da discussão.

São muitos os campos disciplinares e os setores institucionalizados que disputam a autoridade de teorizar sobre a infância: as ciências, as artes, o mercado, o campo jurídico, as religiões, a mídia, os saberes populares. O que significa para cada um deles proteção, participação, tutela e autoria? Que ética habita as distintas teorias que esses campos e setores fazem emergir? É pelo diálogo e pela interação entre campos que é possível construir uma teoria da infância que vá além de evidências e afirmações definitivas, e que possa ampliar a discussão e compreender o fenômeno da infância e as ações e atuações das crianças.

Para finalizar, gostaríamos de compartilhar com o leitor um desafio trazido por Walter Benjamin em seu texto "A obra de arte na era da sua reprodutibilidade técnica", escrito entre 1935/1936. Nele, Benjamin (BENJAMIN, 1987, p. 166) explicita sua preocupação em produzir novos conceitos na teoria da arte que não pudessem ser de modo algum apropriáveis pelo fascismo. Tal preocupação se devia ao crescimento do fascismo e do nazismo, na Alemanha, e à percepção das consequências éticas que a estetização da política impunha ao campo da cultura, sobretudo pelo uso do cinema como propaganda nazista, prática que Hitler assume quando eleito Chanceler, mesmo depois de um frustrado Golpe de Estado. Benjamin vê que a única possibilidade de escapar estava justamente na politização da arte, politizar no sentido de resgatar sua história, a diversidade dos modos de sua produção, o seu dever de indagar e escandalizar.

Do lugar de quem percebe o hálito fascista que é próprio das conjunturas ditatoriais, queremos aqui lançar (e assumir) semelhante desafio: o de produzir teorias sobre a infância que não possam ser de maneira alguma apropriáveis pelo fascismo que se avizinha com a espetacularização da política e a judicialização da vida. Por exemplo, como afirmar a participação e a autoria das crianças sem que essa afirmação possa, jamais, ser apropriada pelos signatários das teses sobre a menoridade penal ou da pedofilia de mercado. Como proteger a criança sem que essa proteção possa, jamais, servir às políticas de tutela e de $\begin{array}{llllll}\text { (C) ETD-Educação Temática Digital } & \text { Campinas, SP } & \text { v.20 } & \text { n.3 } & \text { p.761-780 } & \text { jul./set. } 2018\end{array}$ 
colonização da sua voz? Como escapar, num contexto de judicialização da vida e da política que a ética na pesquisa com crianças seja colonizada pelo saber jurídico? O conselho que nos deixa Benjamin (1987) é que a única maneira de escapar a isso é politizando a teoria que produzimos. Politizar a teoria implica, em cada pesquisa, recolocarmo-nos a pergunta sobre "que é a teoria?" e sobre "que ética está posta na produção dessa teoria?".

Politizar a teoria é assumir que o terreno onde o pesquisador trabalha é o fio de uma navalha onde não há como se equilibrar sem assumir os riscos e as tomadas de decisão.

\section{REFERÊNCIAS}

AMORIM, Marília. O pesquisador e seu outro. Bakhtin nas Ciências Humanas. São Paulo: Musa, 2004.

BAKHTIN, Mikhail. Estética da criação verbal. São Paulo: Martins Fontes, 2003.

BAKHTIN, Mikhail. Para uma filosofia do ato. São Carlos: Pedro e João Editores, 2010.

BARBOSA, Maria Carmen Silveira. A ética na pesquisa etnográfica com crianças: primeiras problematizações. Práxis Educativa. Ponta Grossa, v. 9, n. 1, p. 235-245, jan./jun., 2014.

BENJAMIN, Walter. Obras escolhidas v. I - Magia e técnica, arte e política. São Paulo: Brasiliense, 1987.

BRASIL. Constituição da República Federativa do Brasil. Brasília: Senado, 1988.

BRASIL. Decreto 99.710, de 21 de novembro de 1990. Promulga a Convenção sobre os Direitos da Criança. Diário Oficial da União. Brasília, DF, 22 nov. 1990a.

BRASIL. Lei n 8.069, de 13 de julho de 1990. Estatuto da Criança e do Adolescente. Diário Oficial da União. Brasília, DF, 16 jul. 1990b.

BRASIL. Lei n. 13.257, de março de 2016. Dispõe sobre as políticas públicas para a primeira infância. Diário Oficial da União. Brasília, DF, 9 mar. 2016.

CASTRO, Lucia Rabello de. Os jovens podem falar? Sobre as possibilidades políticas de ser jovem hoje. In: DAYRELL, Juarez; MOREIRA, Maria Ignez Costa; STENGEL, Márci (Org.). Juventudes Contemporâneas: um mosaico de possibilidades. Belo Horizonte: PUCMinas, 2011.

CASTRO, Lucia Rabello de. 0 futuro da infância e outros escritos. Rio de Janeiro: 7 Letras, 2013.

$\begin{array}{llllll}\text { (C) ETD-Educação Temática Digital } & \text { Campinas, SP } & \text { v.20 } & \text { n.3 } & \text { p.761-780 } & \text { jul./set. } 2018\end{array}$


CHRISTENSEN, Pia; PROUT, Alan. Working with ethical symmetry in social research with children. Childhood, v. 9, n. 4, p. 477-497, 2002.

GIDDENS, Anthony. Dimensões da modernidade. In: Sociologia, problemas e práticas. Lisboa: Centro de investigação e estudos de sociologia, n. 4, maio, p. 237-251, 1988.

GRAHAM, Anne; FITZGERALD Robyn. Progressing children's participation: exploring the potential of a dialogical turn. Childhood, v. 17, n. 3, p. 343-359, 2010.

LANSDOWN, Gerison. Children's rights. In: MAYALL, Berry (Ed.). Children's childhoods: observed \& experienced. London: The Falmer Press, 1994.

MATTOS, Amana; PÉREZ, Beatriz Corsino; ALMADA, Carlos Vinícius Ribeiro; CASTRO, Lucia Rabello de. O cuidado na relação professor-aluno e sua potencialidade política. Estudos de Psicologia, v. 18, n. 2, p. 369-377, 2013.

MATTOS, Amana. Conflitos geracionais na escola: a produção das diferenças etárias em contextos hierarquizados. In: I Simpósio em Psicologia Crítica USP - Estabelecendo Diálogos: Teorias Críticas, Psicanálise, Análise de Discurso, Feminismo, Pós-Colonialismo, Epistemologia, Metodologia. São Paulo, 2013.

MAYALL, Berry. Sociologies de l'enfance. In: BROUGÈRE, Gilles; VANDENBROECK, Michel (Dir). Repenser l'education des jeunes enfantes. Bruxelles: P.I.E Peter Lang, 2007.

PEREIRA, Rita Ribes. Um pequeno mundo próprio inserido num mundo maior. In: PEREIRA, Rita Ribes; MACEDO, Nelia Mara Rezende. (Orgs.) Infância em pesquisa. Rio de Janeiro: Nau Editora, 2012.

PRADO, Renata Lopes Costa. A participação de crianças em pesquisas brasileiras das ciências humanas e sociais. Tese (doutorado) - Programa de Pós-graduação em Psicologia Escolar e do Desenvolvimento Humano. Instituto de Psicologia, USP, 2014.

QVORTRUP, Jens. Nove teses sobre a "infância como um fenômeno social". In: Pro-posições. Campinas, v. 22, n.1, p. 199-211, jan./abr., 2011.

QVORTRUP, Jens. Childhood as a Social Phenomenon: an introduction to a series of national reports. In: Eurosocial Report. Vienna: European Centre, n. 36, p. 7-39, 1990.

QVORTRUP, Jens. Infância e política. In: Cadernos de Pesquisa. São Paulo, v. 40, n.141, p. 777-792, set./dez., 2010.

QVORTRUP, Jens. A dialética entre a proteção e a participação. Currículo sem Fronteiras, v. 15, n. 1, p. 11-30, 2015

QVORTRUP, Jens. Sociology of childhood: Conceptual liberation of children. In: MOURITSEN, Flemming; QVORTRUP, Jens (Eds.). Childhood and children culture. Odense: Odense

$\begin{array}{llllll}\text { (C) ETD-Educação Temática Digital } & \text { Campinas, SP } & \text { v.20 } & \text { n.3 } & \text { p.761-780 } & \text { jul./set. } 2018\end{array}$


University Press, 2002 (Versão expandida e revisada de: . Childhood in Europe: a new field of social research. In: CHISHOLM, Lynne et al. (Eds.) Growing up in Europe. Berlin/New York: De Gruyter, 1995).

PINTO, Manuel; SARMENTO, Manuel. As crianças: contextos e identidades. Braga: Centro de Estudos da Criança/ Universidade do Minho, 1997

SGRITTA, Giovanni. La cittadinanza 'negata'. In: MAGGIONI, Guido; BARALDI, Claudio. Cittadinanza dei bambini e costruzione sociale dell'infanzia. Urbino/Itália: Edizioni QuattroVenti, 1997.

SGRITTA, Giovanni; SAPORITI, Angelo. Childhood as a social phenomenon. Implication for future social policy. International comparative research project. National research council. Country report, Italy, v. 13, june, p. 679-690, 1989.

SOARES, Natália Fernandes. Os direitos das crianças nas encruzilhadas da proteção e da participação. Zero-a-Seis. Florianópolis, v. 7, n. 12, p. 8-18, jan. 2005. Disponível em: https://periodicos.ufsc.br/index.php/zeroseis/article/view/2100. Acesso em: 26 fev. 2016. doi: http://dx.doi.org/10.5007/2100.

THOMAS, Nigel. Towards a theory of children's participation. International Journal of Children's Rights. v. 15, p. 199-218, Martinus Nijhoff Publishers, Leiden/Boston, 2007.

YOUNG, Iris Marion. Representação política, identidade e minorias. Lua Nova, n. 67, p. 139190, 2006.

'Revisão gramatical do texto sob a responsabilidade de: Nelson Santiago.

E-mail: nelsoreia@gmail.com 